\title{
PAPER
}

\section{Turning points towards sustainability: integrative science and policy for novel (but real) landscape futures}

\author{
David J. Brunckhorst* \\ Institute for Rural Futures and UNESCO Centre for Bioregional Resource Management, University of New England, \\ Armidale, NSW 2351, Australia
}

\begin{abstract}
Non-metropolitan landscapes are the major theatre of interactions where large-scale alteration occurs precipitated by local to global forces of economic, social and environmental change. However, these regional landscape effects are critical also to local natural resource and social sustainability, ecosystem health through to larger scales of biospheric functioning. The institutions contributing pressures and responses consequently shape future landscapes and in turn influence how social systems, resource users, governments and policy makers perceive those landscapes and their future. These are, in essence, complex social-ecological systems intertwined in a multitude of ways at many spatial scales across time. Over time, the cycles of complex social-ecological systems also reach crossroads, which might be crisis points at which future options are no longer available (possibly because of resource degradation or loss), or turning points where opportunities arise when it is easier to change direction towards more sustainable activities. This paper provides some examples of interdisciplinary research that has provided a holistic integration through close engagement with residents and communities or through deliberately implementing integrative high-risk 'on-ground' experimental models to 'learn by doing'. In the final analysis, each project has characteristically, however, sought to integrate through spatial (if not temporal) synthesis, policy analysis and (new or changed) institutional arrangements that are relevant locally and corporately, as well as at broader levels of government and geography. This has provided transferable outcomes that can contribute real options and adaptive capacity for suitable positive futures.
\end{abstract}

KEY WORDS: Landscape ecology · 'Turning points' · Institutions · Integration · Social-ecological systems $\cdot$ Policy $\cdot$ Natural resource management $\cdot$ Sustainability

Resale or republication not permitted without written consent of the publisher

\section{BACKGROUND AND INTRODUCTION}

Globally, resource crashes and concurrent social dysfunction in rural and regional communities have been at higher levels over the past decade than in recorded history (e.g. Berkes et al. 2003). ${ }^{1}$ Many countries,

${ }^{1}$ See also Cairns J Jr (2004) Small islands: harbingers of Earth's ecological fate? ESEP 2004:29-31, available online at http://www.int-res.com/articles/esep/2004/E48.pdf including Australia, share these characteristics with additional challenges provided by diverse variables such as climate and institutional and policy intransigence (Reeve 1992). Institutional degradation by international aid organisations and the World Bank has pushed many areas of third world countries unnecessarily towards resource crises and associated social dysfunction (see various critiques by Bromley; Bromley 1991,1992).

Increasing demands on landscape ecological function to provide goods to the very highly consumptive 
western world such as USA, Europe and Australia is escalating pressure on local resources and cultures of both east and west. The Amazon and Asia are not alone in the pressures applied by the greedy West for resource extraction (and subsequent social and ecological breakdown). Australia is currently mining its natural resources in unsustainable agricultural production to satisfy 50 million people who live primarily in the USA (also Japan and Europe). This paper focuses on new insights and directions from landscape ecology and analysis of biocultural regions which is particularly relevant to lessons, new directions and novel institutional forms the western world should be turning towards. Because all other countries also have their own culturally defined systems of resource use and management for sustainable rural livelihoods that have a landscape context the ideas presented here might also be of wider use.

Landscapes are shaped by the interaction of social and ecological systems. Past resource use and interacting social-ecological systems have shaped the function and patterns of landscapes. Humans continue to shape the current and future use, productivity and patterns of sustainability of landscapes and whole regions. Efforts to overcome the degradation of ecological resources supporting society and economies are, however, constrained by a lack of understanding of linked socialecological systems (Brunckhorst 2002), and the required eco-ethical change in human values. ${ }^{2}$ These complex systems might be viewed as landscape mosaics (after Forman 1995) - a jigsaw of interacting human and natural systems operating at multiple scales (Brunckhorst 2000a, 2002). Learning and change often appears to be very hard in human dominated systems, however it is becoming clearer that cultural values and institutional arrangements are critically important. Increasingly, these systems end up irreversibly changed with greatly reduced capacity to support human activity.

A growing number of scientists, social and policy commentators and the general public recognise the increasing urgency for human society to become more flexible and adaptable in shifting towards more sustainable resource use, activity and governance. There is a growing consensus, both among policy-makers and researchers that, while biophysical scientific understanding has been crucial to the development of improved agricultural practices, the first priority is now

\footnotetext{
${ }^{2}$ See also Cairns J Jr (2003) Integrating top-down/bottom-up sustainability strategies: an ethical challenge, ESEP 2003:1-6, available online at http://www.int-res.com/ articles/esep/2003/E26.pdf; and Legendre L (2004) Science, culture and (eco-)ethics, ESEP 2004:13-23, available online at http://www.int-res.com/articles/esep/2004/E46.pdf
}

an improved integration of ecology with the economics, sociology institutional arrangements and politics of the transition to a sustainable agriculture and associated resource use (e.g. water).

Systems of natural resource use, local government and regional development need to be compatible with the dynamics of the ecological services and resources involved, and with the social and institutional characteristics of the communities to which resource users belong. The ecological sustainability of future landscapes and their capacity to support human communities and resource use is actually dependent on a range of institutions society uses over time. It will depend less on the ecosystems themselves, though more resilient ones might predominate, leaving fewer options for types of resource use.

The laws that govern the processes of natural systems are fixed; therefore, opportunities to significantly improve resource management outcomes will rely on our ability to modify our social systems to better serve our long-term interest in the natural world. ${ }^{3}$ In practice, however, social change seems to be incredibly difficult to achieve. Nevertheless, society ${ }^{4}$ and its institutions ${ }^{5}$ may need to become more capable of substantial transitions over shorter time scales to adapt to pressures of change, including social ramifications of reduced resource capacity or alternative ecosystem uses and restoration. Such transformations might require novel approaches if humanity is to find realistic solutions to social and environmental sustainability issues providing long-term resilience, because the community can adapt with matching civic skills and knowledge. More effective spatial representation of these features is likely to greatly improve community engagement and participation.

\footnotetext{
${ }^{3} \mathrm{An}$ increasing number of authors are refocusing attention on ecological sustainability issues related to community and administrative arrangements for a more integrative understanding of land use, urban infrastructure and services, local planning, and regional development. This timely shift might be seen as consideration of 'biocultural appropriateness' for institutional, urban and rural capacity building for natural resources management (see, for example, Forman 1995; Gunderson et al. 1995; Hanna et al. 1996; Holling \& Meffe 1996; Omernik \& Bailey 1997; Berkes \& Folke 1998; Brunckhorst 1998, 2000a, 2001, 2002; Knight \& Landres 1998; Reeve 1998; Brunckhorst \& Mouat 2000; Cairns J Jr (2003) Integrating top-down/bottom-up sustainability strategies: an ethical challenge, ESEP 2003:1-6, available online at http://www.int-res.com/articles/esep/2003/E26.pdf)

${ }^{4} \mathrm{~A}$ social system refers to any group of people who interact long enough to create a shared set of understandings, norms, or routines to integrate action and established patterns of dominance and resource allocation

${ }^{5}$ The term 'institutions' refers to sets of formal and informal rules and norms that shape interactions of humans with others and with nature
} 
Future sustainability will require systems of resource governance $^{6}$ that mediate the relationship between society and the economy on one hand, and continuation of ecosystem functional processes on the other. Therefore, the human dimensions of landscapes must be integrated with policies, administrative frameworks and plans to repair and sustain ecological systems and functions.

The term 'integration' as used in this paper, refers to a holistic understanding of complex interacting socialecological systems, rather than approaches that attempt to reassemble separately studied components to elucidate meaning. A whole view of and immersion in real, though complex, interacting systems will encompass unique properties that materialise from the interacting systems, and is likely to provide more realistic and practical solutions for natural resource management and human needs (Brunckhorst 2000a, 2002).

\section{LANDSCAPE INTEGRATION}

Landscapes are a social construct, but they are also inherently diverse and embody a multitude of values for their inhabitants. Rural landscapes include people and communities, resource production and related industries, economies and political institutions, biodiversity and ecological systems (Fig. 1). These components operate at various scales and also interact at a variety of levels. Constant change is the normal state. However, the pressures of change on economies, ecological services and resources, and towns and commu-

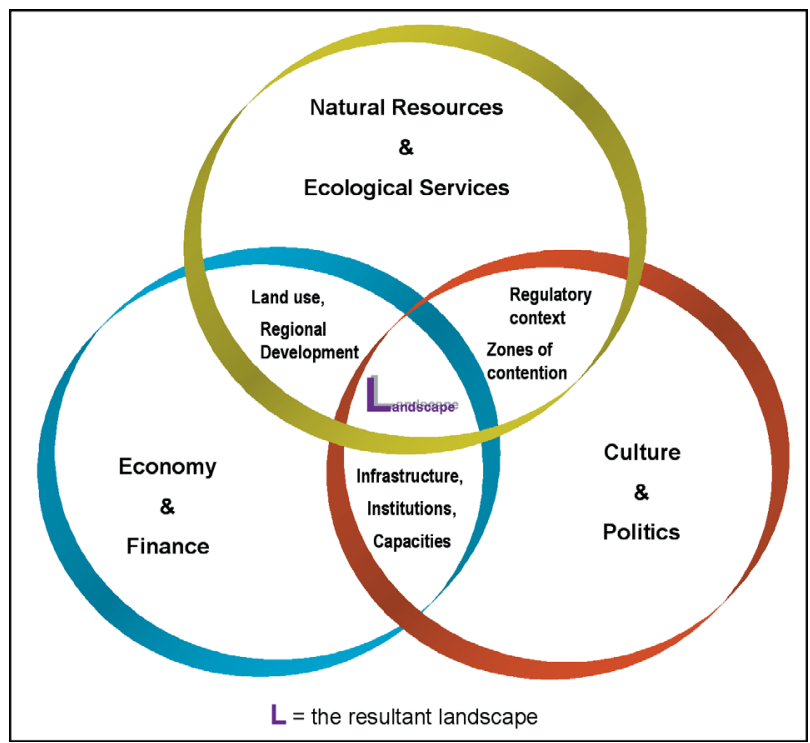

Fig. 1. Landscapes are the result of complex interacting cultural, institutional and physical processes reflecting human values, identity and activities (After Brunckhorst 2002) nities are increasing - indeed, all components are struggling. Single issue or narrowly focused approaches to solutions are unlikely to have lasting benefits. It is recognised that broad, more integrative approaches are required and that a 'suite of tools' for diverse landscape contexts would be useful.

Scale is a critical attribute (see Norton \& Ulanowicz 1992; Slocombe 1993). The landscape scale is the main scale of human interaction with the environment. The landscape-regional context links multiple spatial and temporal scales of biodiversity with human uses and socio-economic imperatives. Human systems for environmental management, however, tend to be more narrowly focused and sectorally based (e.g. fisheries, forestry, national parks). The foundation for a sustainable future is the continuance of ecological processes and functions across multiple spatio-temporal scales (Noss 1983; Norton \& Ulanowicz 1992; Brunckhorst 1995, 1998). It is also becoming evident that actions to sustain ecological systems, flows and functions must be integrated across regional landscapes. Such regions encompass natural areas, human living places (that include rural or oceanic production), and a mosaic of other land uses (Slocombe 1993; Brunckhorst \& Bridgewater 1995). Therefore, actions to sustain ecological systems, flows and function must be integrated across both the human and ecological dimensions of regional landscapes.

There is still too little understanding of the relationship between society and its institutions (including their spatial function) and ecosystems at the scale of regional landscapes or biocultural region (Brunckhorst 2000a). No matter where on the globe, future sustainability will depend on the system of resource governance that mediates the relationship between local communities and the economy on one hand, and continuance of ecosystem functional processes on the other. Methods need to be developed that recognise and account for the scales of influence that interconnected social and ecosystem functional elements have on one another. It will then be possible to demonstrate how ecosystem functional capacity might dictate resource governance (Brunckhorst 1998; Brunckhorst \& Rollings 1999). Real applications include resource planning and management, environmental planning and rehabilitation, rural and agricultural planning,

\footnotetext{
${ }^{61}$ Governance is the capacity of self-organizing systems to govern themselves, and includes not only formal government authorities and agencies, but also an array of private sector and non-governmental organisations as well as communities. Stewardship is the expression of this capacity in the form of "responsible custody" of human ecosystems, and therefore requires competence, vigilance, and ethics of responsibility and accountability for the sustainability of human ecosystems' (Francis \& Shannon 1999, from Shannon 2000)
} 
urbanisation policies, infrastructure planning and more thoughtfully integrated development aid programs.

Human activity is a major change force shaping landscapes. Past change has provided us with our present starting point — there is no point 'winding back the clock'. However many lessons have been learnt, new information is available and there is a pressing need to attempt to influence, in a more 'holistic' and sustainable manner, change towards future (time plus) sustainable rural landscapes and compatible industries. Perhaps this is in part what 'integration' is about - both from applied interdisciplinary research and improved 'learning-by-doing' (adaptive or experimental management) in 'on-ground' (real) complex social-ecological systems contexts. Such integration, to be effective in use, will necessarily include innovative 'redesign' of human institutions and activities and their influences across Australian landscapes.

Enduring ecological, social and economic sustainability requires integrated planning and management of natural resources, ecological functions and primary production across anthropogenic landscapes. This will require changes to social norms, and new institutions and organisational forms. Systems of natural resource use, community functions, local government and regional development need to be compatible with the dynamics of the ecological services and resources involved, and with the social and institutional characteristics of the communities to which resource users belong. These issues are best studied at a regional landscape scale to allow effective integration and redesign of human dominated landscapes.

\section{DISCIPLINARY INTEGRATION AND INNOVATION}

Social systems, ecological function and resource systems and economic systems are highly complex, dependently intertwined networks. These interconnected systems operate across landscapes at various scales often viewed collectively through some geographical framework (for example, within a Local Government area, a water catchment, ecoregion, state). Much recent academic literature, and indeed science policy (e.g. Australian Prime Minister's Science, Engineering and Innovation Council 1998), has been arguing for more integrated multi-disciplinary research in these areas. Approaching the task of studying such systems and bringing methods together to synthesise new insights, new knowledge, new technologies and practical benefits is, in itself, complicated and difficult to frame.

A 'system' is characterised by strong, usually nonlinear interactions and continual feedbacks, thus mak- ing causal resolution very difficult or impossible. Due to the existence of diverse hierarchies, systems are generally non-additive (the whole is not simply a sum of parts) (von Bertalanffy 1968). Classical reductionist science aims to find linear causalities, and basic 'elements' which directly add-up. The interaction of ecosystems, social systems and economic systems of landscapes and regions clearly exhibit characteristics of complex, networked, cross-scale systems (Costanza 1993). These will not be well understood using the methods of classical science. Nevertheless, some means of at least partly isolating the subject of study is needed, as well as some cross-scale, but spatially explicit integrative capability. This capacity is provided through a 'landscape' approach grounded in landscape ecology theory (Forman \& Godron 1986; Kim \& Weaver 1994; Platt 1996; Power 1996; Brunckhorst 1998, 2000a; Odum 1998). Case studies and 'onground' experimental models are also valuable in contributing integration and synthesis (e.g. Ostrom 1990; Gunderson et al. 1995; Brunckhorst et al. 1997; Berkes \& Folke 1998; Brunckhorst 1998, 2003; Coop \& Brunckhorst 2000; Gunderson \& Holling 2001). ${ }^{7}$ There is little focused and coordinated effort to undertake this kind of research. Encouraging new ideas and transdisciplinary research training is problematic, particularly in industrialised countries that focus on reductionist specialisation (often for commercialisation) rather than holistic solutions towards sustainability. ${ }^{8}$

Proponents of any scientific field, method or viewpoint will generally build their arguments on theory. Different approaches and viewpoints, however, are built on different theories, all of which are correct, at least in the sense of being partially tested and credible representations of one part of reality. They do not cover the whole of reality for all systems. Therefore new holistic integrative systems research into the ecological and social processes that occur and interact at various scales across landscapes requires a multi-theoretical basis if integrative theories are lacking. Major theoreti-

\footnotetext{
${ }^{7}$ See also Brunckhorst DJ (2001) Building capital through bioregional planning and biosphere reserves. ESEP 2001:19-32, available online at http://www.int-res.com/ articles/esep/2001/article2.pdf

${ }^{8}$ See also Cairns J Jr (2003) Integrating top-down/bottom-up sustainability strategies: an ethical challenge, ESEP 2003:1-6, available online at http://www.int-res.com/ articles/esep/2003/E26.pdf; Cairns J Jr (2004) Small islands: harbingers of Earth's ecological fate? ESEP 2004:29-31, available online at http://www.int-res.com/articles/esep/ 2004/E48.pdf; Cairns J Jr (2004) Sustainability and specialization, ESEP 2004:33-38, available online at http://www.intres.com/articles/esep/2004/E49.pdf; and Legendre L (2004) Science, culture and (eco-)ethics, ESEP 2004:13-23, available online at http://www.int-res.com/articles/esep/2004/ E46.pdf
} 
cal concepts, approaches and methodologies underpinning this research programme come from integrative fields of landscape ecology, landscape design, systems and hierarchy theory and experimental or adaptive management approaches, urban and regional planning, sociology, psychology, law, institutional analysis and design, new institutionalist economics, environmental and resource sciences, and applied research.

The biophysical components of the biosphere occur in various interacting processes and functions creating patterns at scales from nanometres to thousands of kilometres. Landscape ecology provides a grounded approach to study these systems, including the humans (and their institutions) that shape them (Forman \& Godron 1986; O'Neill et al. 1986; Urban et al. 1987; Forman 1995). Through development and use of computer-based spatial information systems, landscape ecology can be a very powerful tool for integrating and synthesising large amounts of complex data and patterns having explicit contexts and locations on the earth's surface. Design involves courses of action aimed at changing existing situations into preferred ones (Herbert Simon, in Steinitz 1993). Landscape design provides a conceptual framework bringing together ecosystems, resource use and human service and infrastructure needs for a different approach to planning local to regional areas (Lyle 1985; Steinitz 1993; Van Der Ryn \& Cowan 1996; Johnson \& Hill 2001).

As discussed above, systems theory and analysis recognises groups of interacting, interdependent groups (systems) linked by complex exchanges, and influences on each other need to be studied together as much as possible so as to help reflect reality (von Bertalanffy 1968; Costanza 1993). To minimise complexity, but retain the reality of interactions, systems researchers look for boundaries that substantially reduce interactions between system elements or other systems. A considerable body of work has developed around hierarchy theory-multiple scales of such 'boundaries' and 'nesting' occurring in natural and human systems (Pattee 1973; O'Neill et al. 1986; Urban et al. 1987; Hansen \& di Castri 1992; Odum 1998).

With the application of new institutionalist approaches in the social sciences (Eggertsson 1990; North 1990; Black 1997; Challen 2000), derived from various subfields of economics (theory of the firm, industrial organisation, law and political science), there has been considerable theoretical development in recent years with respect to the relationships between institutions and sustainable resource use (Ostrom 1990; Bromley 1991, 1992; Hanna et al. 1996; McKean 1996, 2000; Berkes \& Folke 1998; Brunckhorst 1998; Cortner et al. 1998). This theoretical body is of particular use in integration research programmes, in particular approaches to institutional analysis (Douglas
1986; Ostrom 1990, 1998; Gunderson et al. 1995) and institutional scales and design (Goodin 1996; Hanna et al. 1996; McKean 1996; Singleton 1998; Ostrom et al. 1999).

Transforming institutions and practices, as well as research approaches, requires learning and adaptation. The body of theory and research around active learning and adaptive management (Walters 1986; Walters \& Holling 1990; Gunderson et al. 1995; Walker 1995; Holling 1998) is an important component to research, experimental adaptive models and case studies, as well as practical applications of Panarchy theory. The term 'Panarchy' refers to evolving hierarchical systems with multiple interrelated elements (Gunderson \& Holling 2001) and part of a theoretical framework for studying and understanding the structure in which systems (including natural and social, as well as linked systems such as institutions for natural resources management) are interconnected in evolving, continually adaptive, cycles of growth, accumulation, restructuring and renewal (Gunderson et al. 1995; Gunderson \& Holling 2001). However, Panarchy primarily uses modelling techniques, currently with few data or practical applications. We are beginning to work on more practical, 'grounded' approaches towards a more holistic and practical understanding of real life systems shifts. This 'Turning Points' programme of research (Fig. 2) aims to better understand these transformations, to identify 'leverage' points where a system might be influenced and capable of positive change to foster resilience and sustainability, and to explore the related practical 'on-ground' activity, institutional and policy changes required to make such positive change a reality (Brunckhorst 2000a, 2002, 2003; Brunckhorst \& Coop 2001, 2003).

The bodies of theories that are integrative in nature will be used to identify where there is a need to bring in theoretical insights from some of the other less integrative disciplines. This will lead to new landscape models, the testing of which allows the identification of key areas for institutional innovation and ways to improve feedback between landscape condition and social norms and the functioning of regional economies (Fig. 2). For example, spatial analysis of how social and economic systems, government services and other institutions operate across landscapes with particular ecosystems and productive capacities, might lead to novel applied research as well as new policies, land management and institutions.

There is a clear need to accelerate knowledge, research and novel technologies to assist adaptive change towards more integrated and reflexively competent (adaptive) land-use planning, management and regional development in human dominated agri-ecological landscapes (land use, social, economic, institu- 


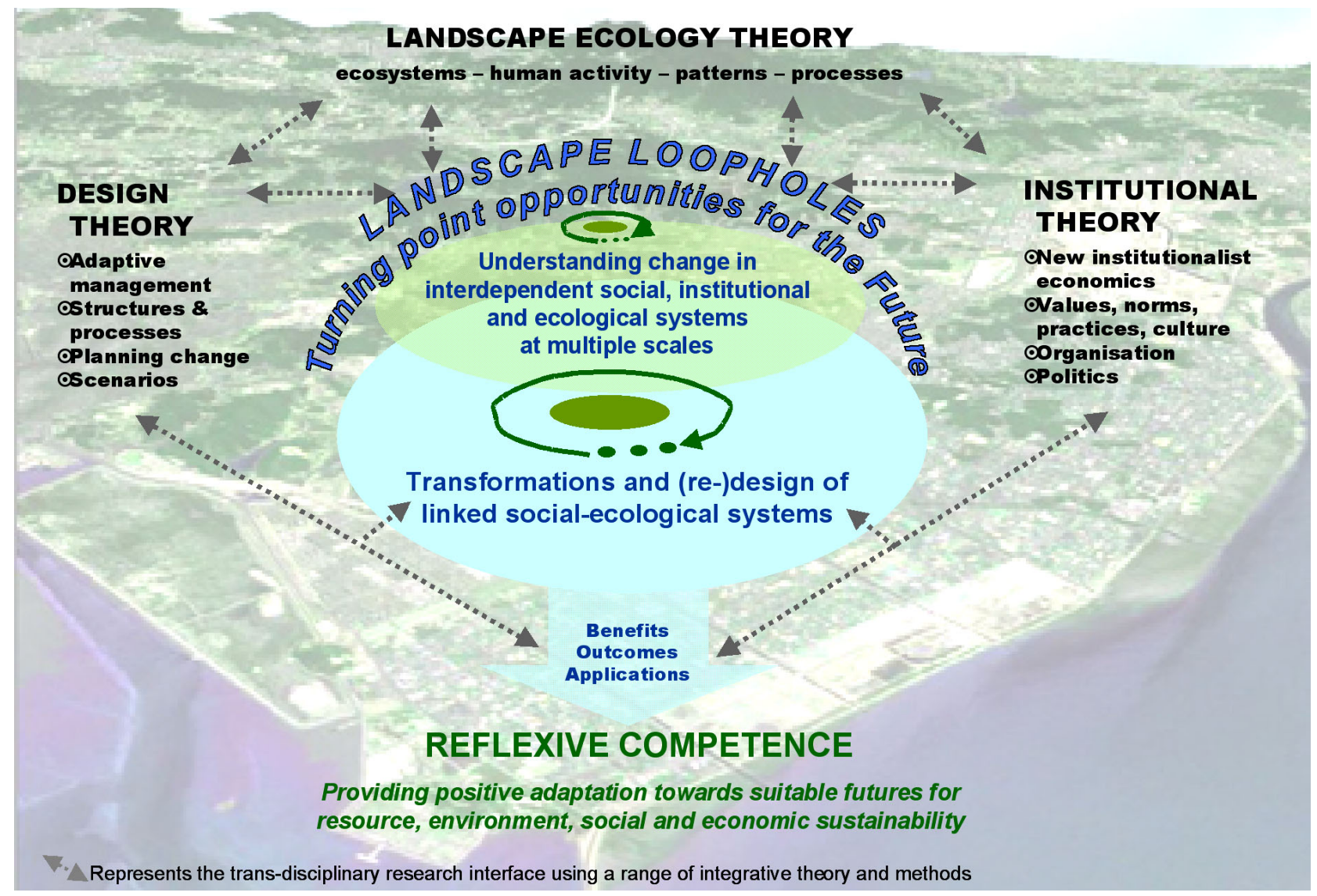

Fig. 2. Diagram showing rationale and linkages for the novel research programme, 'Landscape Loopholes' aimed at building new knowledge and practical adaptive capacity. Specific trans-disciplinary research projects occur at the interface between and across all theoretical and applied fields. For example, sociology, ecology, economics and law are relevant elements of all three integrative theoretical bases above (Original)

tional planning and management, and community service delivery).

Such research is, of necessity, both multi- and trans-disciplinary in nature. However, a much greater effort to facilitate trans-disciplinary research is required, particularly across the integrative fields of landscape ecology, systems theory, Panarchy theory, new institutionalist approaches and experimental adaptive management approaches. ${ }^{9}$ Despite the inherent risks of such innovative research, adoption and transfer is likely to be much higher with the potential of much greater positive (multiplier) out-

${ }^{9}$ This paper is based on a regional landscape ecological paradigm relevant to all nations and continents; however, the first three theoretical bases in this list might be most applicable to developed nations already facing the consequences of resource and environmental degradation, while the landscape 'view', being important culturally to most peoples along with new institutionalist economics (with valuable techniques for understanding local, community and traditional arrangements for resource management), is most relevant to developing county issues comes. Case studies, 'on-ground' experimental models and applications, together with increasing knowledge of linked social-ecological systems and applied research will provide innovative advances and adoption. Such research needs to occur at multiple scales, across property and jurisdictional boundaries, but within appropriate natural resource and socio-economic contexts, to provide options for potential new syntheses for future sustainable landscapes, enterprises and industries.

\section{PRACTICAL RESEARCH INTEGRATION - COMMUNITY AND END-USER ENGAGEMENT}

Together with novel policy synthesis, institutional adaptation and design theory, the landscape approach brings inter-disciplinary research into the dimensions for development of alternative futures, and breakpoint options for transformations explicit to a socialecological landscape (Fig. 2) - the context of people and place (e.g. Freyfogle 1998; Brunckhorst 1998, 
Fig. 3. The Tilbuster Commons project (LWA UNE 40 ) is an example of an applied research project that interfaces across several theoretical fields, with integration of applied interdisciplinary research and relevant outcomes through medium to long term participation with landholders directly engaged in the project (Original)

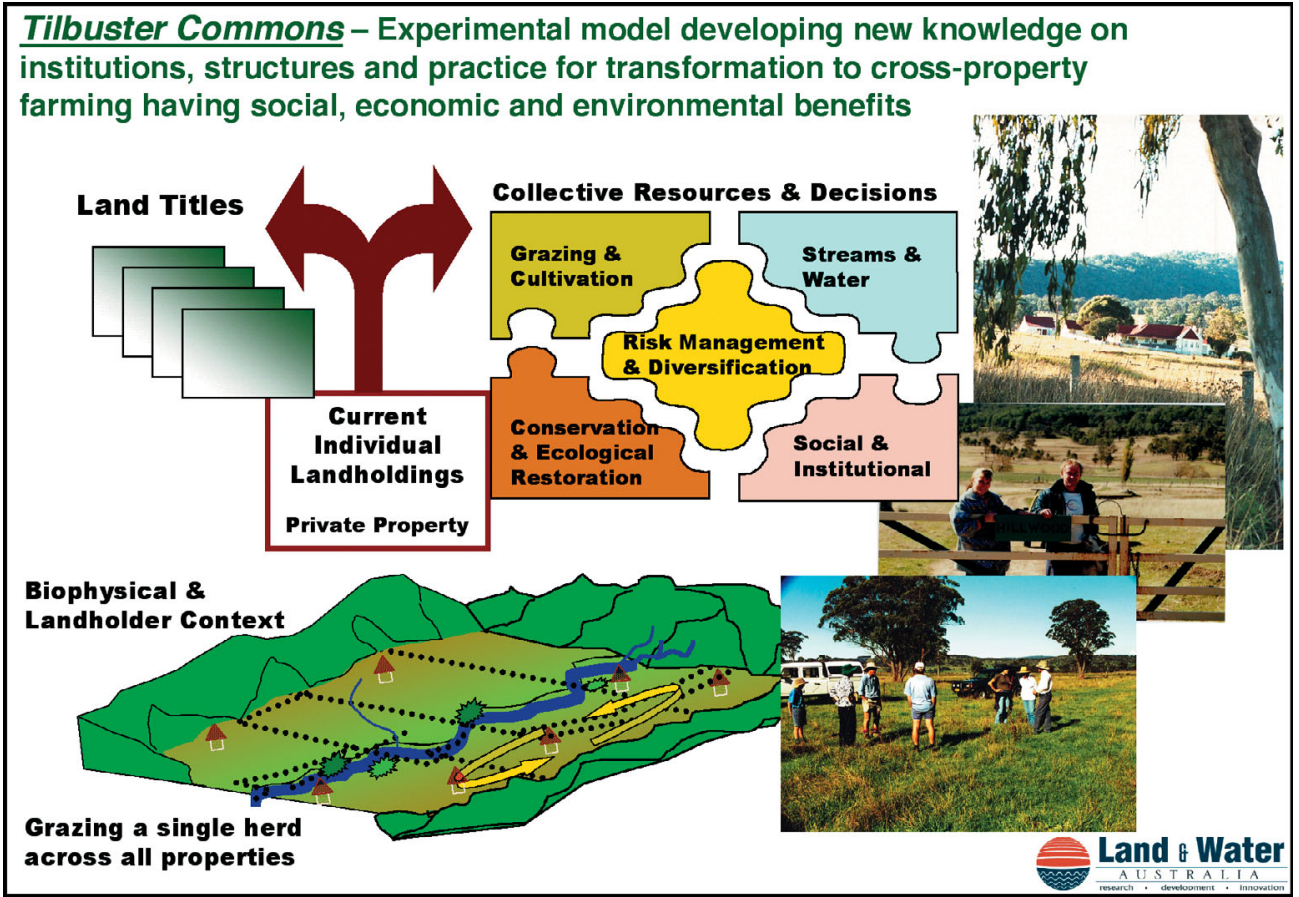

2000a, b, 2002; Brunckhorst \& Coop 2001). ${ }^{10}$ This brings us back to real applications and benefits. The proposed research programme, through linked theories, with linked 'in-situ' research projects (Figs. 2, 3), case studies and spatial analysis and coupled research will contribute a much-needed body of knowledge and technologies. These will supply additional capability for transforming interconnected social-economicecological systems to provide greater competence for positive adaptation towards enduring sustainability.

Some of the Institute's recent projects demonstrate this holistic, integrative approach and practical outcomes. The Tilbuster Commons project (Fig. 3) is an example of an applied research project that interfaces across several theoretical fields, with integration of applied interdisciplinary research and relevant outcomes through medium to long term participation with landholders directly engaged in the project (Brunckhorst 1998, 2003; Coop \& Brunckhorst 1999; Brunckhorst \& Coop 2003; Williamson et al. 2003). It demonstrates and provides synthesis and resolution of Turning Points for transformations towards more sustainable social-ecological systems (Brunckhorst 2000a, b, 2002). Other Turning Points projects such as the NSW Eco-Civic Regionalisation of NSW have been at points of potential change and transformation in terms

${ }^{10}$ See also Brunckhorst DJ (2001) Building capital through bioregional planning and biosphere reserves. ESEP 2001:19-32, available online at http://www.int-res.com/ articles/esep/2001/article2.pdf of coinciding reform of local government and catchment and NRM management arrangements in NSW (Brunckhorst \& Coop 2001). ${ }^{11}$ Eco-industry clustering in rural, regional development with the experimental design of industry ecosystems ${ }^{12}$ provides a Turning Point for rural-based processing and manufacturing industries towards environmentally benign, high efficiency systems of waste reuse that have economic benefits as well.

Such systems and methods will be developed in a number of ways, including case studies, active-adaptive learning experiments ('on-ground' experimental models; e.g. Berkes \& Folke 1998; Coop \& Brunckhorst 1999; Brunckhorst 2000a, b, 2002) and through spatial analysis and computational modelling (grounded with primary data; e.g. Brunckhorst et al. 2002). ${ }^{13}$

\section{CONCLUSION}

Integration research addressing sustainability issues of complex linked social-ecological systems needs to be holistic (cf. a re-aggregation of reductionist studies),

\footnotetext{
${ }^{11}$ See also Brunckhorst DJ, Coop P, Reeve IJ (2004) Eco-civic regionalisation for New South Wales. Report to the New South Wales Government, Dept Lands, available online at: http://www.ruralfutures.une.edu.au/projects/landscape/ ecocivic.htm

${ }^{12}$ See also J. Van der Meulen McNeill \& R. Glencross-Grant, unpubl.

${ }^{13}$ See also Footnote 11
} 
inter- and trans-disciplinary, set in the right context and scale(s) (for a particular social-ecological system and its institutions [or nested operational scales of them]), and incorporating community knowledge, context and culture. The latter should preferably occur through engagement, rather than through specific actions (e.g. consultation) or methods (e.g. Participatory Rural Appraisal).

Integrative research works across areas encompassing sociology, economics, ecosystem management, landscape ecology, planning, agricultural sciences, systems theory, policy, law, institutional analysis, and 'adaptive management' theory. It is non-reductionist, often employing a systems approach and methodologies that are trans-disciplinary in practical application (i.e. decision making, monitoring and management structures, institutional arrangements, policy, resource governance, multiple space and time scales of landscapes and institutional arrangements).

\section{LITERATURE CITED}

Berkes F, Colding J, Folke C (eds) (2003) Navigating socialecological systems: building resilience for change. Cambridge University Press, Cambridge

Berkes F, Folke C (eds) (1998) Linking social and ecological systems: management practices and social mechanisms for building resilience. Cambridge University Press, Cambridge

Black J (1997) New institutionalism and naturalism in sociolegal analysis: institutionalist approaches to regulatory decision making. Law \& Pol'y 19(1):52

Bromley DW (1991) Environment and economy: property rights and public policy. Blackwell, Oxford

Bromley DW (1992) Making the commons work. Theory, practice and policy. Institute for Contemporary Studies Press, San Francisco

Brunckhorst DJ (1995) Sustaining nature and society - a bioregional approach. Inhabit 3:5-9

Brunckhorst DJ (1998) Creating institutions to ensure sustainable use of resources. Habitat Int 22(3):347-354

Brunckhorst DJ (2000a) Bioregional planning: resource management beyond the new millenium. Gordon and Breach, Harwood Academic, Amsterdam

Brunckhorst DJ (2000b) Synergies for social, ecological and economic recovery on newly created commons. In: Dolsak N, Ostrom E (eds) Constituting the commons: crafting sustainable commons in the new millennium. Proceedings of the 8th Biennial Conference of the International Association for the Study of Common Property. University of Indiana, Bloomington, Indiana, p 109-131

Brunckhorst DJ (2002) Institutions to sustain ecological and social systems. J Ecol Manage Restor 3(2):109-117

Brunckhorst DJ (2003) Forming common property resource management institutions. J Ecol Manage Restor 4(1): $72-73$

Brunckhorst DJ, Bridgewater PB (1995) Marine bioregional planning: a strategic framework for identifying marine reserve networks, and planning sustainable use and management. In: Shackell N, Willison M (eds) Marine protected areas and sustainable fisheries. Proceedings of the 2nd International Conference on Science and the Management of Protected Areas, Halifax, Nova Scotia, 1994, p 105-116

Brunckhorst DJ, Bridgewater P, Parker P (1997) The UNESCO Biosphere Reserve program comes of age: learning by doing, landscape models for a sustainable conservation and resource. In: Hale P, Lamb D (eds) Conservation outside reserves. University of Queensland Press, Brisbane, p 176-182

Brunckhorst DJ, Coop P (2001) The influence of social ecologics in shaping novel resource governance frameworks, Chapter XI. In: Higgins V, Lawrence G, Lockie S (eds) Social sciences in natural resource management: theoretical perspectives. Edward Elgar Academic Press, Cheltenham, p 227-240

Brunckhorst DJ, Coop P (2003) Tilbuster Commons: synergies of theory and action in new agricultural commons on private land. J Ecol Manage Restor 4(1):13-22

Brunckhorst DJ, Coop P, Reeve IJ (2002) Designing 'eco-civic regions' for NRM. Final report to Land \& Water Australia on LWA UNE 35 research project: the social and ecological functions of landscapes. Institute for Rural Futures, University of New England, Armidale

Brunckhorst DJ, Mouat D (eds) (2000) Landscape futures. Proceedings of the International Symposium on Landscape Futures (Refereed proceedings of international symposium, Sept. 1999), UNESCO Institute for Bioregional Resource Management and University of New England, Armidale

Brunckhorst DJ, Rollings NM (1999) Linking ecological and social functions of landscapes: I. Influencing resource governance. Nat Areas J 19(1):34-41

Challen R (2000) Institutions, transaction cost and environmental policy: institutional reform for water resources. Edward Elgar (New Horizons in Environmental Economics), Cheltenham

Coop P, Brunckhorst DJ (1999) Triumph of the commons: ageold participatory practices provide lessons for institutional reform in the rural sector. J Environ Manage 6(2):48-56

Coop P, Brunckhorst DJ (2000) Creating contemporary commons to enhance economic productivity: a grazing commons in rural Australia. In: Dolsak N, Ostrom E (eds) Constituting the commons: crafting sustainable commons in the new millennium. Proceedings of the 8th Biennial Conference of the International Association for the Study of Common Property. University of Indiana, Bloomington, Indiana, p 132-154

Cortner HJ, Wallace M, Burke S, Moote M (1998) Institutions matter: the need to address the institutional challenges of ecosystem management. Landscape Urban Plan 40: 159-166

Costanza R (1993) Ecological economic systems analysis: Order and chaos. In: Barbier EB (ed) Economics and ecology: new frontiers and sustainable development. Chapman and Hall, London, p 27-45

Douglas M (1986) How institutions think. Syracuse University Press, New York

Eggertsson T (1990) Economic behaviour and institutions. Cambridge University Press, Cambridge

Forman RTT (1995) Land mosaics: the ecology of landscapes and regions. Cambridge University Press, Cambridge

Forman RTT, Godron M (1986) Landscape ecology. J Wiley and Sons, New York

Francis D, Shannon M (1999) in Shannon MA (2000) Engaging rural people and catchment communities: weaving together the local and global to make our actions count, Chapter 12. In: Brunckhorst DJ, Mouat D (eds) Landscape futures. 
UNESCO Institute for Bioregional Resource Management and University of New England, Armidale, p 5-31

Freyfogle E (1998) Bounded people, boundless lands: envisioning a new land ethic. Island Press/Shearwater Books, Washington, DC

Goodin RE (1996) Institutions and their design. In: Goodin RE (ed) The theory of institutional design. Cambridge University Press, Cambridge, p 1-53

Gunderson LH, Holling CS (eds) (2001) Panarchy: understanding transformations in human and natural systems. Island Press, Washington, DC

Gunderson LH, Holling CS, Light S (eds) (1995) Barriers and bridges to the renewal of ecosystems and institutions. Columbia University Press, New York

Hanna S, Folke C, Mäler K-G (1996) Rights to nature: ecological, economic, cultural and political principles of institutions for the environment. Island Press, Washington, DC

Hansen AJ, di Castri F (eds) (1992) Landscape boundaries: consequences for biotic diversity and ecological flows. Springer-Verlag, New York

Holling CS (1998) Two cultures of ecology. Conserv Ecol 2(2):4

Holling CS, Meffe M (1996) Command and control and the pathology of natural resource management. Conserv Biol 10(2):328-337

Johnson B, Hill K (eds) (2001) Ecology and design: frameworks for learning. Island Press, Washington, DC

Kim KC, Weaver RD (eds) (1994) Biodiversity and landscapes: a paradox of humanity. Cambridge University Press, New York

Knight RL, Landres PB (eds) (1998) Stewardship across boundaries. Island Press, Washington, DC

Lyle JT (1985) Design for human ecosystems: landscape, land use and natural resources. Van Nostrand Reinhold, New York

McKean M (1996) Common-property regimes as a solution to problems of scale and linkage. In: Hanna S, Folke C, Mäler K-G (eds) Rights to nature: ecological, economic, cultural and political principles of institutions for the environment. Island Press, Washington, DC, p 223-244

McKean M (2000) Designing new common property regimes for new landscape futures. In: Brunckhorst DJ, Mouat D (eds) Landscape futures. UNESCO Institute for Bioregional Resource Management and University of New England, Armidale, p 76-98

North DC (1990) Institutions, institutional change and economic performance. Cambridge University Press, Cambridge

Norton BG, Ulanowicz RE (1992) Scale and biodiversity policy: a hierachical approach. Ambio 21(3):244-249

Noss RF (1983) A regional landscape approach to maintain diversity. Bioscience 33(11):700-706

Odum E (1998) Ecological vignettes: ecological approaches to dealing with human predicaments. Harwood Academic, Gordon \& Breach, Amsterdam

Omernik JM, Bailey RG (1997) Distinguishing between watersheds and ecoregions. J Am Water Resour Assoc 33(5):1-15

O'Neill RV, DeAngelis DL, Wade JB, Allen TF (1986) A hierarchical concept of ecosystems. Princeton University Press, New Jersey

Ostrom E (1990) Governing the commons: the evolution of institutions for collective action. Cambridge University

Editorial responsibility: Mary C. Batson (Managing Editor), Oldendorf/Luhe, Germany
Press, Cambridge

Ostrom E (1998) The institutional analysis and development approach. In: Loehman ET, Kilgour DM (eds) Designing institutions for environmental and resource management. Edward Elgar, Cheltenham, p 68-90

Ostrom E, Burger J, Field C, Norgard R, Policansky D (1999) Revisiting the commons: local lessons, global challenges. Science 284(5412):278-282

Pattee HH (1973) Hierarchy theory: the challenge of complex systems. Braziller, New York

Platt RH (1996) Land use and society: geography, law and public policy. Island Press, Washington, DC

Power TM (1996) Lost landscapes and failed economies: the search for a value of place. Island Press, Washington, DC

Reeve IJ (1992) Sustainable agriculture: problems, prospects and policies. In: Lawrence G, Vanclay F, Furze B (eds) Agriculture, environment and society: contemporary issues for Australia. MacMillan, Melbourne, p 208-223

Reeve IJ (1997) Property and participation: an institutional analysis of rural resource management and landcare in Australia. In: Lockie S, Vanclay F (eds) Critical landcare. Centre for Rural Social Research, Charles Sturt University, Australia, p 83-95

Reeve IJ (1998) Commons and coordination: towards a theory of resource governance. In: Epps R (ed) Sustaining rural systems in the context of global change. Proceedings of the Conference of the Joint IGU Commission for the Sustainability of Rural Systems and the Land Use-Cover Change Study Group, University of New England, Armidale, p 54-65

Shannon MA (2000) Engaging rural people and catchment communities: weaving together the local and global to make our actions count, Chapter 12. In: Brunckhorst DJ, Mouat D (eds) Landscape futures. UNESCO Institute for Bioregional Resource Management and University of New England, Armidale, p 5-31

Singleton S (1998) Constructing cooperation: the evolution of institutions of co-management. University of Michigan Press, Ann Arbor

Slocombe DS (1993) Implementing ecosystem-based management: development of theory, practice and research for planning and managing a region. BioScience 43(9):612-622

Steinitz C (1993) A framework for theory and practice in landscape planning. GIS Europe, July 1993:42

Urban DL, O'Neill RV, Shugart HH Jr (1987) Landscape ecology: a hierarchical perspective can help scientists understand spatial patterns. BioScience 37(2):119-127

Van Der Ryn S, Cowan S (1996) Ecological design. Island Press, Washington, DC

Von Bertalanffy L (1968) General system theory: foundations, development, applications. Braziller, New York

Walker B (1995) Conserving biological diversity through ecosystem resilience. Conserv Biol 9(4):747-752

Walters CJ (1986) Adaptive management of renewable resources. MacMillan, New York

Walters CJ, Holling CS (1990) Large-scale management experiments and learning by doing. Ecology 71(6): 2060-2068

Williamson S, Brunckhorst DJ, Kelly G (2003) Reinventing the Common: cross-boundary farming for a sustainable future. Federation Press, Sydney, Australia

Submitted: June 7, 2004; Accepted: September 14, 2004

Proofs received from author(s): September 22, 2004

Published on the web: September 22, 2004 